\title{
Symptomatic muscular sarcoidosis
}

\section{Lessons from a nationwide multicenter study}

Fleur Cohen Aubart, MD, PhD, Salam Abbara, MD, Thierry Maisonobe, MD, Vincent Cottin, MD, Thomas Papo, MD, PhD, Julien Haroche, MD, PhD, Alexis Mathian, MD, PhD, Micheline Pha, MD, Laurent Gilardin, MD, Baptiste Hervier, MD, PhD, Michael Soussan, MD, PhD, Philippe Morlat, MD, PhD, Hilario Nunes, MD, PhD, Olivier Benveniste, MD, PhD, * Zahir Amoura, MD, MSc,*

and Dominique Valeyre, MD*

Neurol Neuroimmunol Neuroinflamm 2018;5:e452. doi:10.1212/NXI.0000000000000452

\section{Abstract \\ Objectives}

To describe clinicopathologic features of muscular sarcoidosis and the associated sarcoidosis phenotype through a nationwide multicenter study.

\section{Methods}

Patients were included if they had histologically proven sarcoidosis and symptomatic muscular involvement confirmed by biological, imaging, or histologic examinations.

\section{Results}

Forty-eight patients (20 males) were studied, with a median age at muscular symptoms onset of 45 years (range 18-71). Four patterns were identified: a nodular pattern (27\%); smoldering phenotype (29\%); acute, subacute, or progressive myopathic type (35\%); and combined myopathic and neurogenic pattern (10\%). In all patterns, sarcoidosis was multivisceral with a median of 3 extramuscular organs involved (mostly lungs, lymph nodes, eyes, and skin) and a prolonged course with long-term use of corticosteroids and immunosuppressive drugs. Muscular patterns differed according to clinical presentation (myalgia, nodules, or weakness), electromyographic findings, muscular MRI, and response to sarcoidosis treatment. The myopathic and neuromuscular patterns were more severe.

\section{Conclusion}

This nationwide study of muscular sarcoidosis allowed the identification of 4 patterns of granulomatous myositis, which differed by phenotypes and the clinical course.

\footnotetext{
*These authors contributed equally to this work.
}

From the AP-HP (F.C.A., S.A, J.H., A.M., M.P., Z.A), Service de Médecine Interne 2, Institut e3m, Hôpital de la Pitié-Salpêtrière, Centre National de Référence Maladies Systémiques Rares, Lupus, Syndrome des anticorps antiphospholipides; Université Paris VI (F.C.A., J.H., O.B.), UPMC, Sorbonnes Universités; AP-HP (T.M.), Département de neurophysiologie et de neuropathologie, Hôpital de la Pitié-Salpêtrière, Paris; Service de Pneumologie (V.C.), Centre des maladies pulmonaires rares, Lyon; AP-HP (T.P.), Service de Médecine Interne, Hôpital Bichat; AP-HP (L.G., B.H., O.B., Z.A.), Service de Médecine Interne et immunologie clinique, Hôpital de la Pitié-Salpêtrière, Paris; AP-HP (M.S.), Service de Médecine Nucléaire, Hôpital Avicenne, Bobigny; Service de Médecine Interne (P.M.), CHU Bordeaux, Bordeaux; AP-HP (H.N., D.V.), Service de Pneumologie, Hôpital Avicenne, Bobigny, France.

Funding information and disclosures are provided at the end of the article. Full disclosure form information provided by the authors is available with the full text of this article at Neurology.org/NN.

The Article Processing Charge was funded by the authors.

This is an open access article distributed under the terms of the Creative Commons Attribution-NonCommercial-NoDerivatives License 4.0 (CC BY-NC-ND), which permits downloading and sharing the work provided it is properly cited. The work cannot be changed in any way or used commercially without permission from the journal. 


\section{Glossary}

$\mathbf{m R S}=$ modified Rankin score.

Sarcoidosis is a multisystemic disease of an unknown cause characterized by the presence of noncaseating granulomas in various organs. ${ }^{1,2}$ Clinical muscular involvement is rare, and few series have been described. ${ }^{3-6}$ This contrasts with the relatively high frequency of a nonsymptomatic presence of granulomas in muscles from patients with sarcoidosis as revealed by autopsy studies. ${ }^{7}$ Three clinical patterns of muscular sarcoidosis have been described ${ }^{3,8,9}$ : a nodular form occurring in young adults, an acute myositis presentation, and a pseudomyopathic form seen in older patients. In previous studies, muscular sarcoidosis had poor outcomes, and permanent motor deficit was frequent. ${ }^{3,10,11}$ However, data on long-term outcomes of this condition are lacking.

We therefore conducted a nationwide retrospective study to describe clinical, biological, radiologic presentations of muscular sarcoidosis and long-term outcomes.

\section{Methods}

We performed a nationwide retrospective multicenter study (2000-2015) including patients with (1) clinical and radiologic presentation consistent with sarcoidosis; (2) histologic presence of noncaseating granulomas; (3) exclusion of other causes of granulomas (all patients underwent an exhaustive search for mycobacterial agents and other causes of infections, hematologic proliferations, and cancers); (4) clinical muscular involvement defined by myalgia and/or a Muscular Research Council score $<5$ in at least 1 tested muscle without an alternative cause; and (5) at least 1 of the following criteria: creatine kinase enzymes $>2 \mathrm{~N}$, myopathic pattern in electrophysiologic studies, muscular inflammation on MRI, multifocal muscular hypermetabolism in ${ }^{18}$ fluorodeoxyglucose positron emission tomography scan and/or granuloma in muscular biopsy. Exclusion criteria were data insufficiency. The patients in whom inclusion body myositis was finally diagnosed were excluded from this cohort study. The patients were recruited through local databases among the participants of the "Groupe Sarcoïdose Francophone" (a French research network working on sarcoidosis and other granulomatous diseases). Detailed information about screening and excluded patients is provided as supplemental material (links.lww.com/NXI/A42).

The study was conducted in compliance with the Good Clinical Practice protocol and the Declaration of Helsinki Principles. According to the current French Legislation (Loi Jardé 2016 and its subsequent amendments legifrance.gouv. fr/affichTexte.do;jsessionid=D8DE76AD02196EE756E078C9212A0C6E.tpdila13v_3?cidTexte=JORFTEXT000032719 520\&categorieLien $=\mathrm{id}$ ), an observational and retrospective study that does not change the routine management of patients does not need to be declared to the local ethics board.

The Fisher exact test was used to compare qualitative variables, and the Kruskal-Wallis test was used to compare quantitative variables. All tests were 2 -sided, and $p<0.05$ was considered statistically significant. The analyses were conducted with GraphPad Prism Version 6.0 (GraphPad software, La Jolla, CA).

\section{Results}

\section{Patients' characteristics}

Forty-eight patients, 28 women and 20 men with median age at muscular symptoms onset of 45 years (range 18-75 years), were included in the analysis. Their demographic and clinical characteristics are detailed in table 1 . All patients had histologic evidence of noncaseating granulomas and a symptomatic muscular involvement. Forty patients had a muscular biopsy (figure S1, links.lww.com/NXI/A41) and thus had a definite neurosarcoidosis, and 8 a probable neurosarcoidosis according to the Zajicek criteria. ${ }^{12}$

\section{General characteristics of symptomatic muscular sarcoidosis}

In patients with symptomatic muscular involvement, sarcoidosis was characterized by a multivisceral involvement with a median of 3 extramuscular localizations per patient. The most frequent localizations concerned the lungs, lymph nodes, skin, and eyes (table 1). Moreover, the heart, CNS, and the skeleton were unexpectedly frequently involved. The outcome was remarkably chronic, and the patients received a protracted treatment (almost all patients were still treated at the end of follow-up, which had a median duration of 6 years).

\section{Patterns of symptomatic muscular sarcoidosis}

According to the historical classification of muscular sarcoidosis, 13 patients had a "nodular" presentation, 16 a "myopathic" presentation, 1 an "acute" presentation of muscular sarcoidosis, and 18 patients were not classified. Thus, we identified 4 patterns of muscular sarcoidosis. These patterns included a nodular, a smoldering, a myopathic, and a combined myopathic and neurogenic pattern. The clinical, biological, and imaging data are detailed in tables 1 and 2. The definitions of these patterns are detailed below but briefly, the presence of motor deficit classified the patient as "myopathic," the presence of nodular lesions without motor deficit as "nodular," and the absence of nodular lesions and motor deficit as "smoldering." Moreover, the presence of a neurogenic pattern in electrophysiological studies, in addition to muscular involvement, 
Table 1 Demographic and clinical characteristics of the patients

\begin{tabular}{|c|c|c|c|c|c|c|}
\hline Median (range) or $\mathbf{n}(\%)$ & $\begin{array}{l}\text { All } \\
(n=48)\end{array}$ & $\begin{array}{l}\text { Nodular form } \\
(n=13)\end{array}$ & $\begin{array}{l}\text { Smoldering } \\
\text { form }(n=14)\end{array}$ & $\begin{array}{l}\text { Myopathic } \\
\text { form }^{\mathrm{a}}(n=17)\end{array}$ & $\begin{array}{l}\text { CNM form } \\
(n=5)\end{array}$ & $p$ Value \\
\hline $\operatorname{Sex}(M / F)$ & $20 \mathrm{M} / 28 \mathrm{~F}$ & $8 \mathrm{M} / 5 \mathrm{~F}$ & $7 \mathrm{M} / 7 \mathrm{~F}$ & $6 \mathrm{M} / 11 \mathrm{~F}$ & $0 \mathrm{M} / 5 \mathrm{~F}$ & - \\
\hline Afro-American & $16(33 \%)$ & $7(54 \%)$ & $3(21 \%)$ & $7(41 \%)$ & 0 & - \\
\hline Age at sarcoidosis diagnosis, y & $42(18-77)$ & $34(22-60)$ & $45.5(18-65)$ & $38(19-77)$ & $64(43-68)$ & 0.02 \\
\hline Age at muscular involvement, y & $45(18-71)$ & $31(22-60)$ & $49.5(18-64)$ & $47(19-68)$ & $64(53-71)$ & 0.005 \\
\hline \multicolumn{7}{|l|}{ Muscular involvement } \\
\hline At onset & $31(65 \%)$ & $11(85 \%)$ & $7(50 \%)$ & $11(65 \%)$ & $3(60 \%)$ & - \\
\hline During follow-up & $17(35 \%)$ & $2(15 \%)$ & $7(50 \%)$ & $6(35 \%)$ & $2(40 \%)$ & - \\
\hline Time from sarcoidosis onset to muscular signs, y & $4(0.2-28)$ & $1.6(0.2-3)$ & $4(1-9)$ & $9(3-20)$ & $14.1(0.2-28)$ & - \\
\hline \multicolumn{7}{|l|}{ Sarcoidosis involvement } \\
\hline Lung & $38(79 \%)$ & $10(77 \%)$ & $9(64 \%)$ & $16(94 \%)$ & $4(80 \%)$ & - \\
\hline Lymph nodes & $37(77 \%)$ & $9(69 \%)$ & $11(79 \%)$ & $15(88 \%)$ & $3(60 \%)$ & - \\
\hline Skin & $20(42 \%)$ & $7(54 \%)$ & $5(36 \%)$ & $8(47 \%)$ & $1(20 \%)$ & - \\
\hline Liver/spleen & $10(21 \%)$ & $1(8 \%)$ & $3(21 \%)$ & $6(35 \%)$ & 0 & - \\
\hline Heart & $17 / 45(38 \%)$ & $5 / 12(42 \%)$ & $5 / 13(38 \%)$ & $7 / 17(41 \%)$ & $1 / 4(25 \%)$ & - \\
\hline Skeletal & $7(15 \%)$ & $1(7 \%)$ & $5(36 \%)$ & $1(6 \%)$ & 0 & - \\
\hline Eye & $17(35 \%)$ & $3(23 \%)$ & $7(50 \%)$ & $6(35 \%)$ & $1(20 \%)$ & - \\
\hline Kidneys & $4(8 \%)$ & $1(8 \%)$ & 0 & $3(17 \%)$ & 0 & - \\
\hline CNS & $4(8 \%)$ & $1(8 \%)$ & $2(14 \%)$ & 0 & $1(20 \%)$ & - \\
\hline \multicolumn{7}{|l|}{ Clinical symptoms and signs at onset } \\
\hline Motor deficit (MRC) ${ }^{b}$ & $21(44 \%)$ & 0 & 0 & $17(100 \%)$ & $4(80 \%)$ & - \\
\hline Myalgias & $36(75 \%)$ & $11(85 \%)$ & $14(100 \%)$ & $10(59 \%)$ & $2(40 \%)$ & - \\
\hline Nodular lesions & $13(27 \%)$ & $13(100 \%)$ & 0 & $1(6 \%)$ & 0 & - \\
\hline Amyotrophy & $4(8 \%)$ & 0 & 0 & $3(17 \%)$ & $1(20 \%)$ & - \\
\hline Modified Rankin score (onset), median (range) & $2(1-4)$ & $2(1-3)$ & $1(1-3)$ & $3(2-4)$ & $3(1-4)$ & $<0.0001$ \\
\hline
\end{tabular}

Abbreviations: $\mathrm{CNM}=$ combined neurogenic and myopathic; $\mathrm{LL}=$ lower limbs; $\mathrm{MRC}=$ muscle research council; $\mathrm{UL}=$ upper limbs; $\mathrm{y}=\mathrm{years}$.

The modified Rankin score (mRS) (0, no symptoms; 1, no significant disability despite symptoms; 2 , slight disability, unable to perform all previous activities but able to look after without assistance; 3, moderate disability, requiring some help but able to walk without assistance; 4 , moderately severe disability, unable to walk without assistance; 5 , severe disability, incontinent, and requiring constant nursing; and 6, dead) was evaluated at baseline (first evaluation of muscular symptoms) and at the last visit.

a One patient appears in these 2 columns because he had a nodular pattern followed 2 years later by a myopathic pattern. To evaluate motor deficit, the MRC scale was used ( 0 , noncontraction; 1 , trace of contraction; 2 , active movement with gravity eliminated; 3 , active movement against gravity; 4 , active movement against gravity and resistance; and 5, normal power). Motor deficit was defined by an MRC score $<5$ in at least 1 upper or lower limb.

${ }^{\mathrm{b}}$ When the 2 sides were not similar, the lowest MRC score was taken.

classified the patient in the "combined myopathic and neurogenic" group. Among the myopathic pattern, we observed an acute (when the onset of symptoms was $<48$ hours), a subacute ( 48 hours -1 month), and chronic form (if the onset of symptoms was $\geq 1$ month).

The nodular pattern was defined by the presence of clinical muscular palpable nodules, myalgias $(85 \%)$, but no motor deficit. Muscular MRI was almost always abnormal when performed $(83 \%)$, whereas, conversely, electromyographic studies had a lower tendency to detect myopathic changes in this presentation (normal in $60 \%$ of cases). This pattern was frequently seen at the onset of the disease $(85 \%)$, with the onset of muscular symptoms in young patients (median 31 years), often of Afro-American origin (54\%). Cutaneous involvement of sarcoidosis was particularly frequent (54\%).

The smoldering pattern referred to patients with constant myalgias but without nodules, motor deficits, or amyotrophy. Muscular MRI was frequently normal (67\% of cases). Patients were rarely Afro-American (21\%), and relatively old at sarcoidosis diagnosis (median 45.5 years). Muscular 
Table 2 Laboratory, imaging, electrophysiologic, and histologic data

\begin{tabular}{|c|c|c|c|c|c|}
\hline & All $(n=48)$ & $\begin{array}{l}\text { Nodular form } \\
(n=13)\end{array}$ & $\begin{array}{l}\text { Smoldering form } \\
(n=14)\end{array}$ & $\begin{array}{l}\text { Myopathic form } \\
(n=17)\end{array}$ & $\begin{array}{l}\text { CNM form } \\
(n=5)\end{array}$ \\
\hline \multicolumn{6}{|l|}{ Elevated CK } \\
\hline n (\%) & $20 / 44(45 \%)$ & $6 / 11(55 \%)$ & $6 / 13(46 \%)$ & $9 / 16(56 \%)$ & $0 / 4$ \\
\hline Level $^{\mathbf{b}}$, median (range) & $620(250-7,000)$ & $363(250-1,300)$ & $1,050(451-1,500)$ & $1,018(286-7,000)$ & \\
\hline Abnormal muscular MRI & $16 / 19(84 \%)$ & $5 / 6(83 \%)$ & $1 / 3(33 \%)$ & $10 / 10(100 \%)$ & $0 / 0$ \\
\hline Hyper T2 & 6 & 3 & 1 & 2 & \\
\hline Gadolinium enhancement & 10 & 3 & 0 & 7 & \\
\hline Other changes & 7 & 3 & 0 & 4 & \\
\hline Abnormal electromyogram & $29 / 34(85 \%)$ & $3 / 5(60 \%)$ & $8 / 10(80 \%)$ & $14 / 15(93 \%)$ & $5 / 5(100 \%)$ \\
\hline Myopathic changes & 25 & 2 & 7 & 14 & 2 \\
\hline Other abnormalities & 7 & 1 & 1 & 0 & 5 \\
\hline${ }^{18}$ FDG PET scan & 6 & 2 & 3 & 1 & 0 \\
\hline Muscle hypermetabolism & $2(33 \%)$ & 0 & 2 & 0 & \\
\hline Muscle biopsy & $40 / 48$ & $10 / 13$ & $10 / 14$ & $16 / 17$ & $5 / 5$ \\
\hline Granulomas & 40 & 10 & 10 & 16 & 5 \\
\hline Other changes & 4 & 0 & 0 & 0 & 4 \\
\hline
\end{tabular}

Abbreviations: $\mathrm{CK}=$ creatine kinase; $\mathrm{CNM}=$ combined myopathic and neurogenic; $\mathrm{PET}$ = positron emission tomography.

a One patient appears in these 2 columns because he had a nodular pattern, followed 2 years later by a myopathic pattern.

${ }^{\mathrm{b}}$ Median CK levels of patients with elevated CK levels.

involvement occurred during follow-up of sarcoidosis in $50 \%$ of cases, with a median time from sarcoidosis onset to muscular signs of 4 years. Skeletal (36\%) and ophthalmic (50\%) involvements were remarkably frequent in this presentation.

The myopathic pattern was defined by the presence of motor deficit with myalgias in $60 \%$ of cases. Electrophysiologic studies showed myopathic changes in $93 \%$ of cases. Motor deficit was usually proximal but 2 patients had a predominant distal pattern and one had a predominant involvement of upper limbs with bicipital deficit. We observed 3 cases (18\%) with an acute onset of muscular symptoms ( 1 at the onset of sarcoidosis and 2 during the follow-up of a previously diagnosed sarcoidosis) and $14(82 \%)$ with a subacute or progressive (or chronic) onset. This pattern occurred sometimes many years after sarcoidosis diagnosis (median 9 years). Thoracic involvement was particularly frequent (94\%). Two patients had hypercalcemia.

Finally, the combined myopathic and neurogenic pattern was identified in 5 patients based on the electrophysiologic profile, which showed pure motor $(n=2)$, sensorimotor $(n=1)$, sensory $(n=1)$, or pluriradicular $(n=1)$ neuropathy, symmetrical $(n=3)$ or asymmetrical $(n=2)$, with predominance in the lower limbs $(n=4)$ or upper limbs $(n=1)$ without an alternative cause. All these patients had granulomas in muscular biopsy (see below). The electromyogram also displayed myopathic changes in 2 cases and abnormal spontaneous activity in 2 cases. The identification of this pattern was confirmed by muscular biopsy findings. In 2 patients, biopsies showed the presence of granuloma in the nerve and muscle. In 2 patients, it showed perivascular granulomas with lymphocytic infiltration of the vessels, with fibrinoid necrosis in 1 case. In the last case (corresponding to the polyradicular pattern), the nerve was not biopsied. Muscular biopsy showed diffuse granulomas. This patient also had pleocytosis in cerebrospinal fluid.

\section{Follow-up, treatments, and outcomes}

The median follow-up duration was 6 years (range 1-27). Therapeutic regimens and clinical course are presented in table 3. Thirty patients were treated with steroids alone as a first-line therapy. All experienced a degree of improvement (partial or complete), except 1 patient who had a worsening of the motor deficit. For this patient, methotrexate was added allowing partial remission.

The nodular pattern of all but 1 patient had a modified Rankin score ( $\mathrm{mRS}$ ) of 0 at the end of follow-up. The nodular pattern was characterized by a high rate of relapsing-remitting course, with 54\% having more than 1 flare-up during the follow-up. Likewise, these patients were frequently still undergoing treatment with an immunosuppressive drug at the end of follow-up. The smoldering pattern typically had a monophasic course without relapses $(71 \%)$. Immunosuppressive 
Table 3 Follow-up and treatments

\begin{tabular}{|c|c|c|c|c|c|c|}
\hline & $\begin{array}{l}\text { All } \\
(n=48)\end{array}$ & $\begin{array}{l}\text { Nodular } \\
\text { form }^{\mathrm{a}}(n=13)\end{array}$ & $\begin{array}{l}\text { Smoldering } \\
\text { form }(n=14)\end{array}$ & $\begin{array}{l}\text { Myopathic } \\
\text { form }^{\mathrm{a}}(n=17)\end{array}$ & $\begin{array}{l}\text { CNM form } \\
(n=5)\end{array}$ & $p$ Value \\
\hline Follow-up, median (range) & 6 yrs (1-27) & 9 yrs (1-23) & 4 yrs (1-19) & 9 yrs (1-27) & 4 yrs (2-5) & - \\
\hline \multicolumn{7}{|l|}{ Treatments } \\
\hline Steroids & $46(96 \%)$ & $12(92 \%)$ & $14(100 \%)$ & $17(100 \%)$ & $4(80 \%)$ & - \\
\hline Hydroxychloroquine & $14(29 \%)$ & $3(23 \%)$ & $8(57 \%)$ & $3(17 \%)$ & 0 & - \\
\hline Immunosuppressive drug ${ }^{b}$ & $29(60 \%)$ & $7(54 \%)$ & $9(64 \%)$ & $11(64 \%)$ & $3(60 \%)$ & - \\
\hline Methotrexate & $27(56 \%)$ & $6(46 \%)$ & $8(57 \%)$ & $11(64 \%)$ & $2(40 \%)$ & - \\
\hline Azathioprine & $5(10 \%)$ & $2(15 \%)$ & $2(14 \%)$ & $1(6 \%)$ & 0 & - \\
\hline Mycophenolate & $7(15 \%)$ & $1(8 \%)$ & $3(21 \%)$ & $2(12 \%)$ & $2(40 \%)$ & - \\
\hline Cyclophosphamide & $7(15 \%)$ & $1(8 \%)$ & $2(14 \%)$ & $3(18 \%)$ & $2(40 \%)$ & - \\
\hline TNFa antagonists & $3(6 \%)$ & $1(8 \%)$ & $2(14 \%)$ & 0 & 0 & - \\
\hline \multicolumn{7}{|l|}{ Muscular relapses } \\
\hline 1 flare & $31(65 \%)$ & $6(46 \%)$ & $10(71 \%)$ & $10(59 \%)$ & $5(100 \%)$ & - \\
\hline$>1$ flare & $14(29 \%)$ & $7(54 \%)$ & $4(29 \%)$ & $4(24 \%)$ & 0 & - \\
\hline Progressive disease & $3(6 \%)$ & 0 & 0 & $3(18 \%)$ & 0 & - \\
\hline \multicolumn{7}{|l|}{ Last visit } \\
\hline Steroids & $39(81 \%)$ & $8(61 \%)$ & $13(93 \%)$ & $17(100 \%)$ & $4(80 \%)$ & - \\
\hline Immunosuppressive drug & $18(38 \%)$ & $6(46 \%)$ & $2(14 \%)$ & $6(35 \%)$ & $3(60 \%)$ & - \\
\hline $\begin{array}{l}\text { Modified Rankin scale (end of follow-up), } \\
\text { median (range) }\end{array}$ & $0(0-4)$ & $0(0-2)$ & $0(0-1)$ & $1(0-4)$ & $3(0-3)$ & $<0.0001$ \\
\hline
\end{tabular}

Abbreviation: $\mathrm{CNM}=$ combined myopathic and neurogenic.

a One patient appears in these 2 columns because he had a nodular pattern, followed 2 years later by a myopathic pattern. A flare was defined by an increase of symptoms or worsening of biological or imaging data requiring an increase in steroids above $20 \mathrm{mg} / \mathrm{d}$. A progressive disease was defined by a progressive worsening of symptoms and/or biological and/or imaging data without a remission phase.

${ }^{b}$ At least one among methotrexate, azathioprine, mycophenolate mofetil, cyclophosphamide, or TNFa antagonists.

drugs were less frequently used (14\%). Hydroxychloroquine was used in 8 cases, with efficacy against myalgias in 6 cases (75\%). The myopathic presentation was characterized by a progressive pattern in $18 \%$ of cases, despite corticosteroid treatment in all patients. Finally, the combined myopathic and neurogenic pattern was characterized by frequent sequelae as demonstrated by a higher mRS at the end of follow-up. ${ }^{13}$ Of note, 1 patient had a nodular pattern, followed 2 years later by a myopathic pattern.

\section{Discussion}

Symptomatic muscular sarcoidosis is a rare condition observed in association with a multivisceral involvement of sarcoidosis, a protracted course and the need for longduration treatments. This is in accordance with other localizations of neurosarcoidosis. ${ }^{14-16}$ Four muscular patterns were individualized according to clinical manifestations, electromyography, MRI, and pathology: nodular, smoldering, myopathic and combined myopathic, and neurogenic patterns. These patterns differed by age of patients and sarcoidosis presentation and outcomes. The nodular pattern, associated with frequent skin involvement, and the combined myopathic and neurogenic pattern, combining nerve and muscle involvements, may reflect the contiguous spreading of granulomas. The myopathic pattern was associated with intrathoracic involvement. The initial and final $\mathrm{mRS}$ sere different between groups. Moreover, the nodular or myopathic patterns were more frequently seen in Afro-American patients.

In the literature, granulomatous myositis, which usually occurs in the setting of sarcoidosis, is reported in a few series of more than 10 patients $^{3-5}$ and in other smaller studies. ${ }^{8-11}$ Asymptomatic granulomatous involvement is reported to be as frequent as $80 \%$ in autopsic studies. ${ }^{7}$ In our study, all the patients had a symptomatic and multisystemic disease with at least 2 involved organs. However, some patients did not have the classical intrathoracic localization of sarcoidosis. We identified 5 patients with only muscular and heart disease, corresponding to nodular $(\mathrm{n}=2)$, smoldering $(\mathrm{n}=1)$, 
myopathic $(\mathrm{n}=1)$, or combined myopathic and neurogenic $(\mathrm{n}=1)$ patterns.

The classification of granulomatous myositis relied until now on the palpable nodular, acute myositis, and chronic myopathy types. However, this classification does not allow integrating all patients. We suggest that the 4 patterns we described could be used to better classify patients with granulomatous myositis and help to guide treatment.

Some rare phenotypes were also described in our study, such as predominant distal or upper limbs involvement, which were rarely reported previously. Vasculitis presentation of neurosarcoidosis was observed in 2 cases in association with muscular involvement. ${ }^{13}$

The course of muscular sarcoidosis differs depending on muscular patterns: the nodular type is readily relapsingremitting, although the myopathic one may have a progressive course. Thus, patients having a nodular type are commonly prescribed immunosuppressive drugs. We noted that hydroxychloroquine was a useful treatment for smoldering disease, even if this drug may rarely cause muscular damage. Of note, myalgias often responded to hydroxychloroquine.

This study has several limitations. First, the retrospective design and heterogeneity of patients and treatments do not allow drawing conclusions regarding treatment efficacy. The limited number of patients may have influenced the determination of statistical significance for several comparisons.

This study highlighted 4 patterns of muscular sarcoidosis, which differed according to age of patients, sarcoidosis presentation, and outcomes.

\section{Author contributions}

All the authors (F. Cohen Aubart, S. Abbara, T. Maisonobe, V. Cottin, T. Papo, J. Haroche, A. Mathian, M. Pha, L. Gilardin, B. Hervier, M. Soussan, P. Morlat, H. Nunes, O. Benveniste, Z. Amoura, and D. Valeyre) contributed to drafting/revising the manuscript for content and study design, as well as analysis and interpretation of the data. F. Cohen Aubart, S. Abbara, T. Maisonobe, L. Gilardin, and H. Nunes contributed to the acquisition of data. F. Cohen Aubart conducted the statistical analysis. T. Maisonobe centrally reviewed the histologic analyses. F. Cohen Aubart, Z. Amoura, and D. Valeyre coordinated the study.

\section{Acknowledgment}

The authors thank the members of the Groupe Sarcoïdose Francophone who contributed to taking care of the patients (in alphabetical order): Diane Bouvry, Catherine Chapelon, Makoto Miyara, Laurent Perard, Pascal Seve, Yurdagul Uzunhan, and Nathalie Costedoat-Chalumeau.

\section{Study funding}

No targeted funding reported.

\section{Disclosure}

F. Cohen Aubart reports no disclosures. S. Abbara consulted for Alexion, received research support from Fondation pour la Rechere Medicale. T. Maisonobe reports no disclosures. V. Cottin received personal fees from Actelion, Boehringer Ingelheim, Bayer, Biogen Idec, Gilead, GSK, MSD, Novartis, Roche, Sanofi, Promedior, Celgene, Galapagos, and grants from Ingelheim, served as an associate editor for Respiration, section editor of the European Respiratory Journal, and received research support from Boehringer, Roche. T. Papo, J Haroche, A. Mathian, M. Pha, L. Gilardin, B. Hervier, M. Soussan, P. Morlat, and H. Nunes report no disclosures. O. Beneniste served on the scientific advisory board for CSL Behring, Novartis, and LFB, received travel funding from CSL Behring and LFB, consulted for Novartis and CSL Behring, received research support from LFB, Novartis, Shire, CSL Behring, DGOS/INSERM, PHRC, AFM, and The Myositis Association. Z. Amoura reports no disclosures. D. Valeyre served on the scientific advisory boards for IPF (supported by Roche and Boehringer Ingelheim), received travel funding and/or speaker honoraria from ATS, ERC, CPLF, and Astra Zenecca. Full disclosure form information provided by the authors is available with the full text of this article at Neurology.org/NN.

Received September 3, 2017. Accepted in final form February 12, 2018.

\section{References}

1. Valeyre D, Prasse A, Nunes H, Uzunhan Y, Brillet PY, Muller-Quernheim J. Sarcoidosis Lancet 2014;383:1155-1167.

2. Judson MA. The clinical features of sarcoidosis: a comprehensive review. Clin Rev Allergy Immunol 2015;49:63-78.

3. Le Roux K, Streichenberger N, Vial C, et al. Granulomatous myositis: a clinical study of thirteen cases. Muscle Nerve 2007;35:171-177.

4. Maeshima S, Koike H, Noda S, et al. Clinicopathological features of sarcoidosis manifesting as generalized chronic myopathy. J Neurol 2015;262:1035-1045.

5. Mozaffar T, Lopate G, Pestronk A. Clinical correlates of granulomas in muscle. J Neurol 1998;245:519-524.

6. Silverstein A, Siltzbach LE. Muscle involvement in sarcoidosis. Asymptomatic, myositis, and myopathy. Arch Neurol 1969;21:235-241.

7. Perry A, Vuitch F. Causes of death in patients with sarcoidosis. A morphologic study of 38 autopsies with clinicopathologic correlations. Arch Pathol Lab Med 1995;119: 167-172.

8. Wolfe SM, Pinals RS, Aelion JA, Goodman RE. Myopathy in sarcoidosis: clinical and pathologic study of four cases and review of the literature. Semin Arthritis Rheum 1987;16:300-306.

9. Gardner-Thorpe C. Muscle weakness due to sarcoid myopathy. Six case reports and an evalation of steroid therapy. Neurology 1972;22:917-928.

10. Douglas AC, Macleod JG, Matthews JD. Symptomatic sarcoidosis of skeletal muscle. J Neurol Neurosurg Psychiatry 1973;36:1034-1040.

11. Wallace SL, Lattes R, Malia JP, Ragan C. Muscle involvement in Boeck's sarcoid. Ann Intern Med 1958;48:497-511.

12. Zajicek JP, Scolding NJ, Foster O, et al. Central nervous system sarcoidosis-diagnosis and management. QJM 1999;92:103-117.

13. Souayah N, Chodos A, Krivitskaya N, Efthimiou P, Lambert WC, Sharer LR. Isolated severe vasculitic neuropathy revealing sarcoidosis. Lancet Neurol 2008;7:756-760.

14. Bitoun S, Bouvry D, Borie R, et al. Treatment of neurosarcoidosis: a comparative study of methotrexate and mycophenolate mofetil. Neurology 2016;87:2517-2521.

15. Burns TM, Dyck PJ, Aksamit AJ, Dyck PJ. The natural history and long-term outcome of 57 limb sarcoidosis neuropathy cases. J Neurol Sci 2006;244:77-87.

16. Cohen Aubart F, Galanaud D, Haroche J, et al. Neurosarcoidosis: diagnosis and therapeutic issues [in French]. Rev Med Interne 2016;38:393-401. 


\section{Neurology \\ Neuroimmunology \& Neuroinflammation}

\section{Symptomatic muscular sarcoidosis: Lessons from a nationwide multicenter study}

Fleur Cohen Aubart, Salam Abbara, Thierry Maisonobe, et al.

Neurol Neuroimmunol Neuroinflamm 2018;5;

DOI 10.1212/NXI.0000000000000452

This information is current as of March 16, 2018

\section{Updated Information \& Services}

References

Citations

Subspecialty Collections

Permissions \& Licensing

Reprints including high resolution figures, can be found at: http://nn.neurology.org/content/5/3/e452.full.html

This article cites 16 articles, 1 of which you can access for free at: http://nn.neurology.org/content/5/3/e452.full.html\#\#ref-list-1

This article has been cited by 1 HighWire-hosted articles: http://nn.neurology.org/content/5/3/e452.full.html\#\#otherarticles

This article, along with others on similar topics, appears in the following collection(s):

All Neuromuscular Disease

http://nn.neurology.org//cgi/collection/all_neuromuscular_disease Cohort studies

http://nn.neurology.org//cgi/collection/cohort_studies

Information about reproducing this article in parts (figures,tables) or in its entirety can be found online at:

http://nn.neurology.org/misc/about.xhtml\#permissions

Information about ordering reprints can be found online: http://nn.neurology.org/misc/addir.xhtml\#reprintsus

Neurol Neuroimmunol Neuroinflamm is an official journal of the American Academy of Neurology.

Published since April 2014, it is an open-access, online-only, continuous publication journal. Copyright Copyright $\odot 2018$ The Author(s). Published by Wolters Kluwer Health, Inc. on behalf of the American Academy of Neurology. All rights reserved. Online ISSN: 2332-7812.

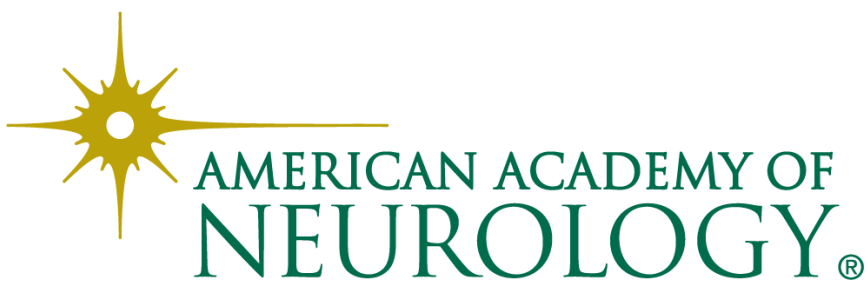

